FOLIA

HORTICULTURAE

Ann. 20/2, 2008, 111-112

Corrigendum

DOI: $10.2478 /$ fhort-2013-0120

\title{
Corrigendum to \\ „Lavandula angustifolia Mill. \\ as a natural host of Cucumber mosaic virus (CMV)"
}

\author{
FOLIA \\ HORTICULTURAE
}

Ann. 20/1, 2008, 61-79

\author{
Tadeusz Kobytko ${ }^{1}$, Piotr Dańda ${ }^{1,}$ \\ Beata Hasiów ${ }^{2}$, Natasza Borodynko², Henryk Pospieszny ${ }^{2}$ \\ ${ }^{1}$ Department of Botany, University of Agriculture in Kraków, \\ 29 Listopada 54, 31-425 Kraków, Poland \\ ${ }^{2}$ Institute of Plant Protection, Department of Virology and Bacteriology, \\ Węgorka 20, 60-318 Poznań, Poland \\ email: zbotaniki@bratek.ogr.ar.krakow.pl
}

Authors and publisher regret that in the mentioned article an error occurred. The incorrect photography is correctly reproduced on the following page. 


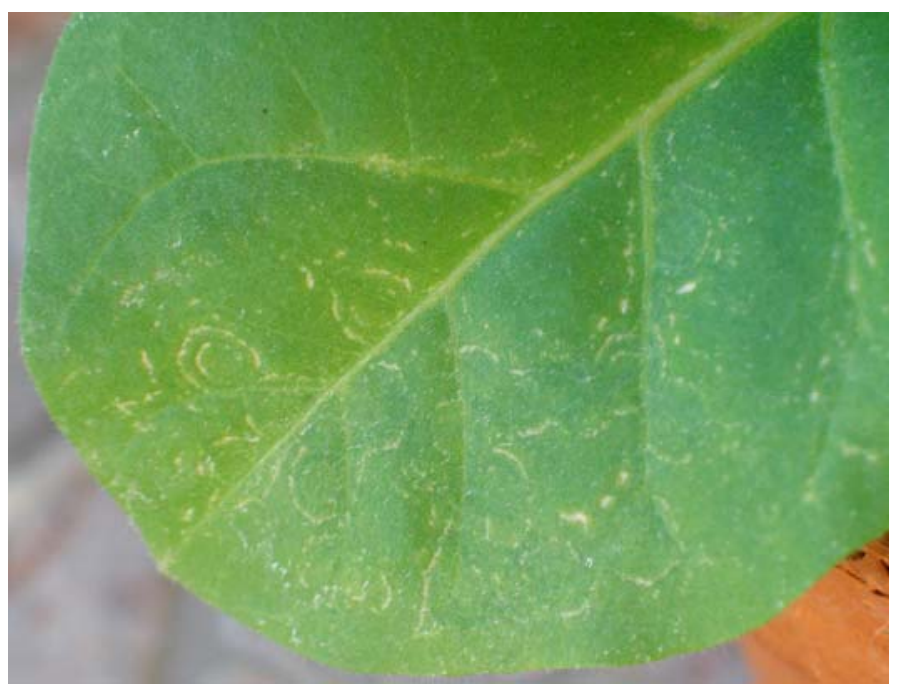

Fig. 4. Local symptoms on the infected leaves of Nicotiana tabacum 'Xanthi'

- Lycopersicon esculentum Mill. 'Potentat' - after 8 days developing mosaic and growth stunting.

- Spinacia oleracea L. - after 3 days chlorotic spots and subsequently chlorosis, mottling and malformation of leaves.

- Vigna unguiculata L. 'Black Eye' - after 5-7 days local necrotic brown spots.

The stability of the virus in the sap from Nicotiana tabacum 'Xanthi' was determined using Chenopodium quinoa plants:

thermal inactivation point (TIP) $55-60^{\circ} \mathrm{C}$,

longevity in vitro $1-2$ days,

dilution end point (DEP) $\log _{10}$ minus $3-4$.

The absorbance readings in DAS-ELISA test were as follows:

tested material $\quad 0.234-0.161$

positive control $\quad 0.209-0.230$

negative control $0.002-0.005$

Multiple sequences alignment performed using Mega 4 revealed 99\% nucleotide and amino acid similarity between the investigated isolate and the isolate of CMV from the Netherlands signed RT67 belonging to subgroup II (Deyong et al. 2005). 